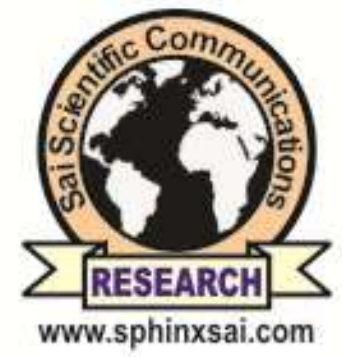

International Journal of ChemTech Research CODEN (USA): IJCRGG, ISSN: 0974-4290, ISSN(Online):2455-9555

Vol.11 No.08, pp 274-282,

2018

\title{
Analytical Detection of Triterpenoids Present in the Hydroalcoholic Extract of Ipomoea Aquatica Forssk. in South India
}

\author{
Sasikala $M^{\star 1}$ and Sundaraganapathy $R^{2}$ \\ ${ }^{1}$ Research Scholar, Faculty of Pharmacy, Karpagam University, Karpagam Academy of \\ Higher Education, Coimbatore - 641 021, Tamil Nadu, India \\ ${ }^{2}$ Dean, Faculty of Pharmacy, Karpagam University, Karpagam Academy of Higher \\ Education, Coimbatore - 641 021, Tamil Nadu, India
}

\begin{abstract}
Introduction: Qualitative analysis will help in the detection of phytoconstituents present in the herbal source accurately. The preliminary phytochemical screening and the thin layer chromatographic analysis are found more simple and sensitive and selective techniques in this way.Aim and Objective:The research was aimed to reveal the secondary metabolites like triterpenoids by using chemical tests and TLC methods. Methods: The tests for detecting triterpenoids were using Salkowski' sreagent and Sulphur powder tests. The TLC parameters were set silica gel $\mathrm{G}$ as adsorbent, Toluene: Ethyl acetate in the ratio of 9.3:0.7v/v as mobile phase, UV light of longer wavelength at $365 \mathrm{~nm}$ as detection wavelength and $\mathrm{R}_{\mathrm{f}}$ value as qualitative respect. Results and Discussion:The phytochemical tests were shown positive results for triterpenoids. The TLC analysis stated that the presence of nearly five different fluorescence spots with $\mathrm{R}_{\mathrm{f}}$ values of $0.06,0.11,0.23,0.36$ and 0.59 respectively. Conclusion:Hence, revealing new class of lipophilliccomponents will assist to improve herbal drug products in the global market. This study could be used in research laboratories for detecting similar type of compounds using TLC analysis. Definitely this will give the good for opportunity for isolating out many therapeutically acting compounds.

Key words : Salkowski, lipophillic, triterpenoids, $\mathrm{R}_{\mathrm{f}}$ value, water spinach,TLC.
\end{abstract}

\section{Introduction}

Triterpenoids, which are widely distributed natural compounds, are usually classified into three groups: acyclic, tetracyclic and pentacyclic. Triterpenoids have been shown with anti-cancer, anti-inflammatory, antiproliferative, and anti-Alzheimer activities. A large number of bioactive pentacyclictriterpenoids, such as oleanolic acid, glycyrrhizin, glycyrrhetinic acid, ursolic acid, betulin, betulinic acid and lupeol have shown multiple biological activities with apparent effects on glucose absorption, glucose uptake, insulin secretion, diabetic vascular dysfunction, retinopathy and nephropathy. The versatility of the pentacyclictriterpenes provides a promising approach for diabetes management [1-2].

Sasikala M et al /International Journal of ChemTech Research, 2018,11(08): 274-282.

DOI= http://dx.doi.org/10.20902/IJCTR.2018.110834 
Terpenoids are chemically lipid-soluble compounds and they can be extracted with petroleum ether generally. Sesquiterpene lactones, diterpenes, sterols and less polar triterpenoids extraction can be also performed by using benzene, ether and chloroform. Ethyl acetate and acetone extracts contain oxygenated diterpenoids, sterols and triterpenoids. Ethanol, methanol and water led to the extraction of highly oxygenated namely polar triterpenes as well as triterpenoid and sterol glycosides. Total extraction of the material carried out by any polar solvents such as acetone, aqueous methanol (\%80) and aqueous ethanol and then re-extraction with hexane, chloroform and ethyl acetate is also leads to successive extraction of terpenoids and sterols [3-4].

TLC is a primary, easy to use and solvent used are unhazardus with no requirement of sophisticated instruments. Usually it is composed of stationary phase and mobile phase, which are performed on a sheet of solid surface such as glass, plastic, aluminum foil that is coated with absorbent material such as silica powder, aluminum oxide and cellulose, which is called as stationary. Mobile phase may consist of single or mixture solvents depending on extracts to separate. This mobile phase is drawn up through the stationary phase by capillary action allowing separation of various compounds on the basis of their solubility and retardation in stationary phase and mobile phase. Separation is achieved by competition of the solute molecules and the mobile phase for binding places on the stationary phase. The most common stationary phase used is a silica gel which is polar in nature, in case if two compounds in extracts have different polarity, highly polar compound will have strong interaction with silica and separated out initially in no time. Fewer polar compounds will separate in second position that has little interaction with stationary phase. On contrary, non polar compound will separate last, which would have non interaction with the stationary runs a longer distance on the plate. The complete understanding of handling TLC is handy for designing research to analysis, separate medicinal significant compounds. Optimization of the solvent system for TLC profiling for identification of amino acid, amines, alkaloids and secondary metabolites of curable plants is highly useful for production of medicinally prominent medicines and novel pharmaceutical products [5-6].

\section{Experimental Procedure}

\section{Materials}

The planned plant contents are tabulated in the table 01. The instruments, chemicals/reagents and glass wares/apparatus practical for the research are represented in the table 02 , table 03 and table 04 individually.

\section{Miscellaneous}

Aluminium foil, Muslin cloth, Filter paper, Tripod stand, Test tube holders and test tube stands and butter paper.

\section{Methods}

\section{Plant Collection, drying and powdering}

The plant was collected from Parambikulam - Aliyar Riverine in Pollachi. The collected portions of the plant were washed with distilled water three times. They were allowed to dry under shade kept over the news paper. Then the half dried portions were cut into small pieces using stainless steel knife and kept under shade only for drying completely. It took 22 days for complete drying. The dried material was pulverized into coarse powder by means of manual blender. The powdered plant material was stored in air tight containers at $4.0^{\circ} \mathrm{C}$ for further use. $350.0 \mathrm{~g}$ of coarse powder of drug was weighed and was taken in a $5000.0 \mathrm{ml}$ Round bottomed flask. Petroleum ether was added to remove the fatty matters associated with the powder. The solvent retained was evaporated at room temperature after rinsing for few minutes. Then the dried defatted powder was immersed in $2000.0 \mathrm{ml}$ of solvents which comprises $1000.0 \mathrm{ml}$ of distilled water and $1000.0 \mathrm{ml}$ of ethanol (50:50 $\mathrm{v} / \mathrm{v})$. After 7 days, the content of extraction was strained through a muslin cloth. The marc was separated from the menstrum. The extract was kept at $40.0^{\circ} \mathrm{C}$ for concentration and evaporation at the same temperature. Then the completely dried extract was cooled to room temperature and weighed [7-8]. 


\section{Preliminary Phytochemicals Evaluation}

\section{Tests for Triterpenoids}

\section{Salkowski's test}

$1-2 \mathrm{mg}$ of the sample dissolved in $1.0 \mathrm{ml}$ of chloroform and $1.0 \mathrm{ml}$ of concentrated sulphuric acid. Formation of red colour at lower layer indicated the presence of steroiods and formation of yellow colour at lower layer indicated the presence of triterpenoids.

\section{Sulfur powder test}

Small amount of sulphur powder to the test solution was added and it had sink at the bottom[7-15].

\section{Thin Layer Chromatographic Analysis}

The existing constituents were separated by using proper mobile phase which was opteddepend on trial and error method [16-33].

\section{Chromatographic parameters}

\section{Stationary phase selection}

Principle: Adsorption

Support material: Glass plate

Dimension of the plate: $20.0 \times 10.0 \mathrm{~cm}$

Adsorbent: Silica gel G

Method of thin layer preparation: Pouring method

Layer thickness: $1.0 \mathrm{~mm}$

Plate activation temperature: at $105.0^{\circ} \mathrm{C}$ for one hour

\section{Mobile phase selection}

Chamber: Twin trough mobile phase chamber

Chamber dimension: $20.0 \times 10.0 \mathrm{~cm}$

Mobile phase selected for separation:

Toluene: Ethyl acetate (9.3:0.7 v/v).

Chamber saturation time: 45.0 minutes

Fluorescence detection: at $365.0 \mathrm{~nm}$ (Longer wavelength)

Calculation of $\mathrm{R}_{\mathrm{f}}$ value:

$\mathrm{R}_{\mathrm{f}}=\frac{\text { Distance travelled by the solute from the sample application position }}{\text { Distance travelled by the solvent from the sample application position }}$

Ideal $\mathrm{R}_{\mathrm{f}}$ value: $0.1-0.9$

\section{Results and Discussion}

The tests specific for triterpenoids were shown positive results and the details are denoted in the figure 01 and in the table 05.The chromatographic parameters were optimized through trial and error method and it is notified in the figure 02 . The profile of TLC was done with the set specifications and those are designated in the figure 03 and table 06.The appearance of lipophillic five numbers of triterpenoids were confirmed by the various qualitative studies commonly meant for herbal analysis [34-38]. 


\section{FIGURES AND TABLES:}

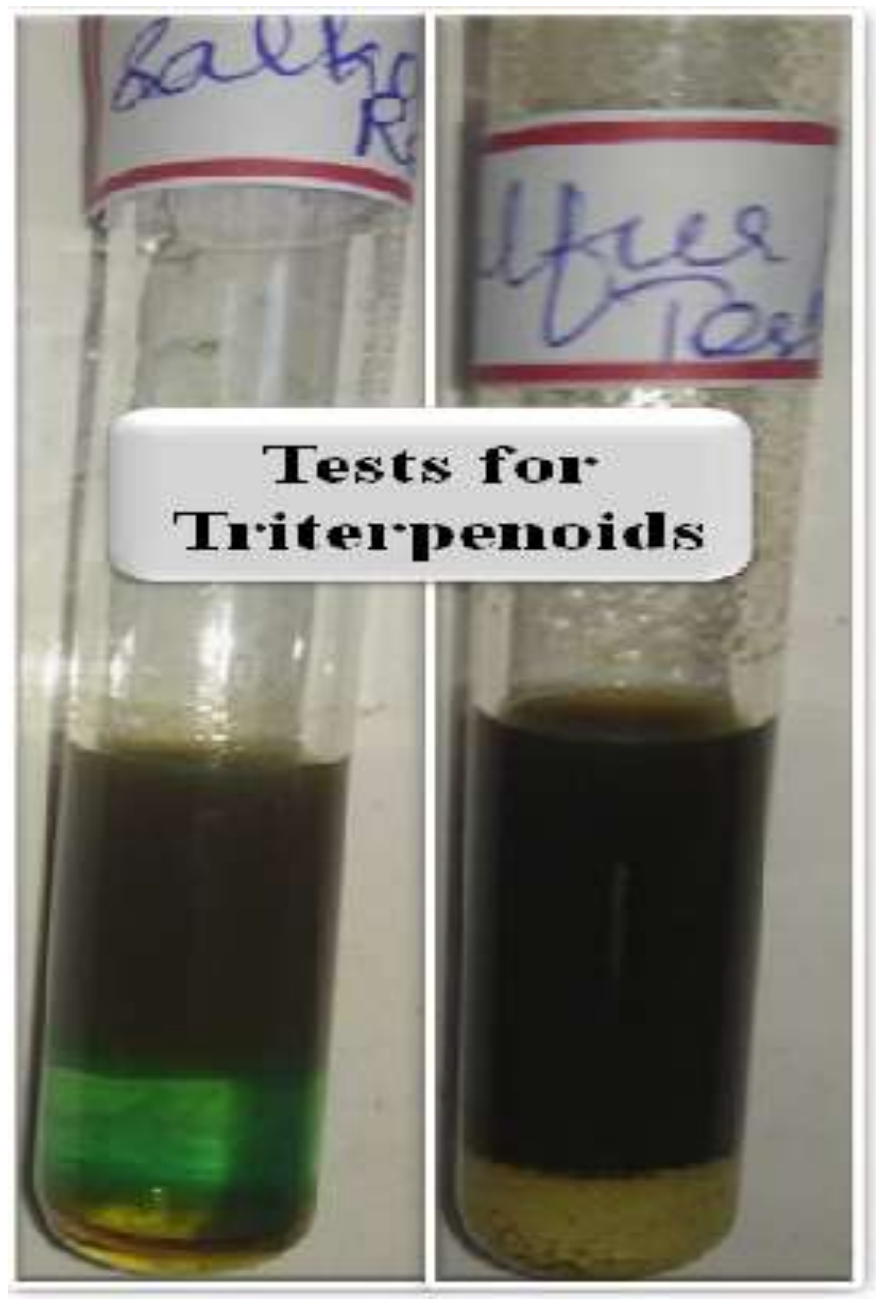

Figure 01: Preliminary Phytochemical Tests for Triterpenoids

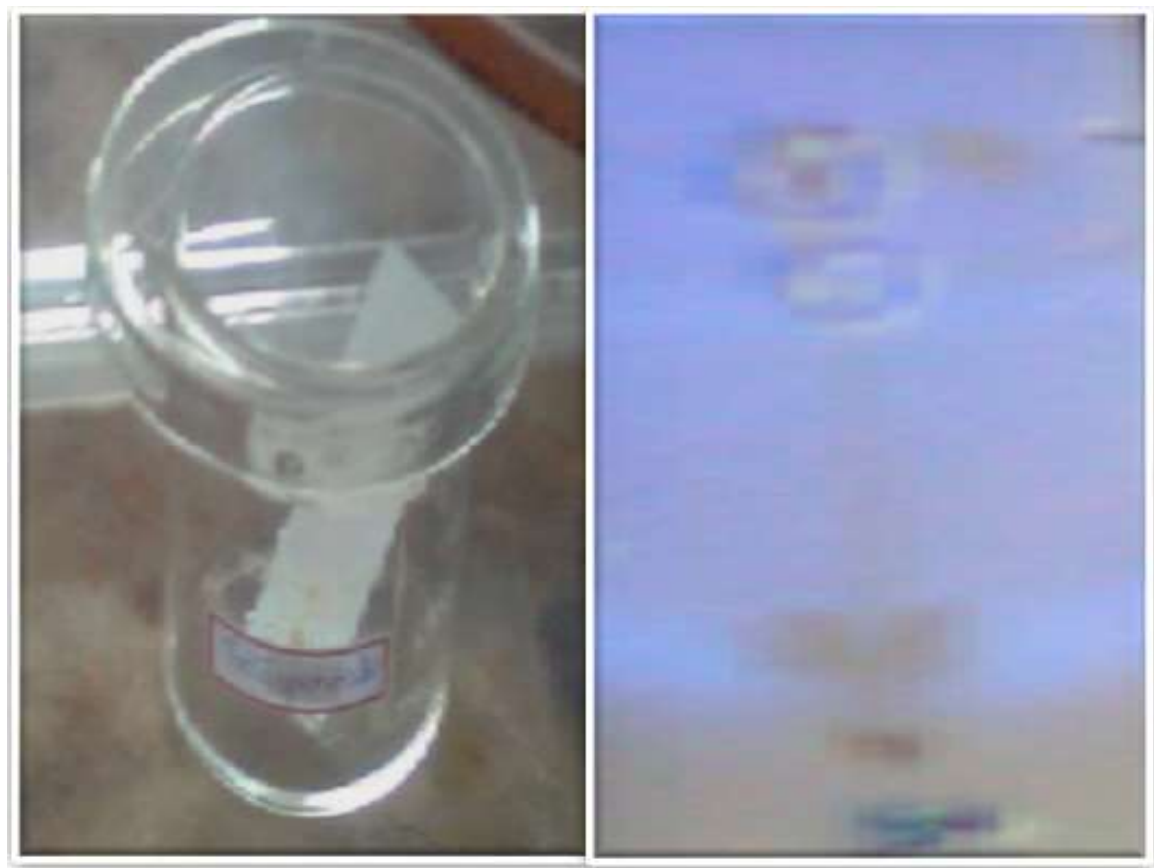

Figure 02: TLC for mobile phase selection (Trial and error method) 


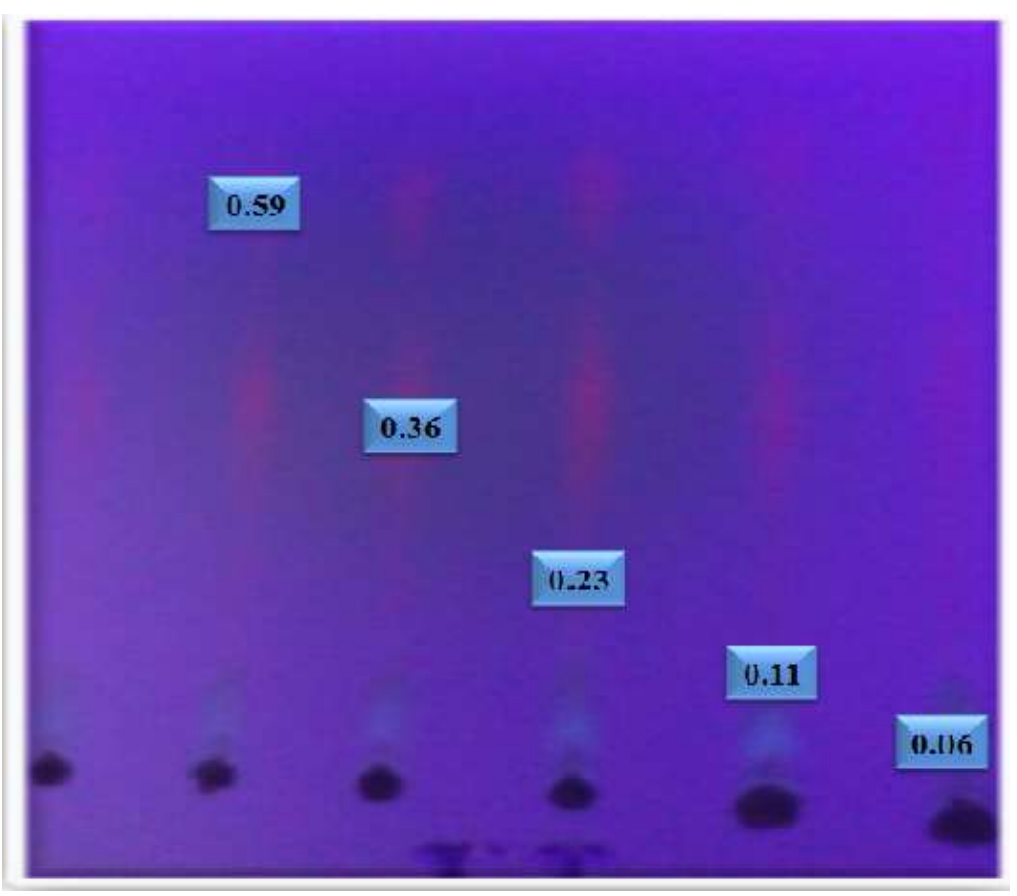

Figure 03: TLC Profile for Triterpenoids in Hydroalcoholic extract of Ipomoea aquatica

Table 01: Plant details

\begin{tabular}{|c|c|c|}
\hline S. No. & Parameters & Subject \\
\hline 1. & Plant Name & Water Spinach, River Spinach \\
\hline 2. & Botanical Name & Ipomoea aquatica FORSSK. \\
\hline 3. & Family & Convolvulaceae \\
\hline 4. & Location & Parambikulam - Aliyar Riverine, Pollachi \\
\hline 5. & Part of the plant & Whole plant \\
\hline 6. & Authentication No. & BSI/SRC/5/23/2017/Tech./3269 \\
\hline 7. & Place of Authentication & BSI, Coimbatore-641003, Tamil Nadu, India \\
\hline
\end{tabular}

Table 02: Instruments used

\begin{tabular}{|c|c|c|}
\hline S. No. & Name of the Instrument & Model Name \\
\hline 1. & Precision Balance & Wensar \\
\hline 2. & Hot plate & Cintex \\
\hline 4. & Electrical Water bath & Technico \\
\hline 5. & UV cabinet & CAMAG and Deep Vision \\
\hline
\end{tabular}

Table 03: Chemicals/Reagents used

\begin{tabular}{|r|c|c|c|}
\hline S.No. & Name of the Reagent & Company & Location \\
\hline 1. & $\begin{array}{c}\text { Petroleum Benzine boiling range } 60.0^{\circ} \mathrm{C}- \\
80.0^{\circ} \mathrm{C} \text { GR (Petroleum ether) }\end{array}$ & $\begin{array}{c}\text { Merck Specialities Private } \\
\text { Limited }\end{array}$ & $\begin{array}{c}\text { Mumbai }- \\
400018\end{array}$ \\
\hline 2. & Ethanol AR $99.9 \%$ & $\begin{array}{c}\text { Jiangsu Huaxi International } \\
\text { Trade Co., Ltd. }\end{array}$ & China \\
\hline 3. & Distilled water & & \\
\hline 4. & Toluene (Sulphur free) & $\begin{array}{c}\text { Reachem Laboratory Chemicals } \\
\text { Private Limited }\end{array}$ & $\begin{array}{c}\text { Chennai }- \\
600098\end{array}$ \\
\hline 5. & Ethyl acetate LR & S d Fine chemicals Private \\
Limited & $\begin{array}{c}\text { Mumbai }- \\
400030\end{array}$ \\
\hline 6. & Silica gel G for TCL & LobaChemie Private Limited & $\begin{array}{c}\text { Mumbai }- \\
400005\end{array}$ \\
\hline
\end{tabular}


Table 04: Glass wares/Apparatus used

\begin{tabular}{|r|c|c|c|}
\hline \multicolumn{1}{|c|}{$\begin{array}{c}\text { S. } \\
\text { No. }\end{array}$} & Name of the Glassware & Capacity & Brand Name \\
\hline 1. & Round bottomed flask & $1000.0 \mathrm{ml}$ & Riviera \\
\hline 2. & Funnel & Medium Size & Sh Borosilicate Glass \\
\hline 3. & Beaker & $1000.0 \mathrm{ml}$ & Borosilicate Glass \\
\hline 4. & Measuring cylinder & $10.0 \mathrm{ml}$ & Riviera \\
\hline 5. & Measuring cylinder & $50.0 \mathrm{ml}$ & Sh Borosilicate Glass \\
\hline 6. & China dish & Big \& Small size & Chinese Porcelain \\
\hline 7. & Stirrer & Small size & Sh Borosilicate Glass \\
\hline 8. & Conical flask & $250.0 \mathrm{ml}$ & Borosilicate Glass \\
\hline 9. & Test tubes & $10.0 \mathrm{ml}$ & Borosilicate Glass \\
\hline 10. & Pipettes & $5.0 \mathrm{ml}$ & Borosilicate Glass \\
\hline 11 & $\begin{array}{c}\text { Mobile phase chamber } \\
\text { (Twin trough) }\end{array}$ & $20 \times 10 \mathrm{~cm}$ & CAMAG \\
\hline 12 & Beaker & $250.0 \mathrm{ml}$ & Borosilicate Glass \\
\hline 13. & Petridish lid & Medium size & Borosil S - Line \\
\hline
\end{tabular}

Table 05: Report for Preliminary Phytochemical Tests forTriterpenoids

\begin{tabular}{|r|c|c|c|c|}
\hline \multicolumn{1}{|c|}{$\begin{array}{c}\text { S. } \\
\text { No. }\end{array}$} & $\begin{array}{c}\text { Phyto- } \\
\text { constituents }\end{array}$ & Chemical test & Observation & Inference \\
\hline 1. & \multirow{2}{*}{$\begin{array}{c}\text { Triterpenoids } \\
\text { test }\end{array}$} & Salkowski's test & $\begin{array}{c}\text { Yellow colour at } \\
\text { lower layer }\end{array}$ & + \\
\cline { 3 - 5 } 2. & Sulphur powder & $\begin{array}{c}\text { Sulphur sinks at } \\
\text { the bottom of } \\
\text { the solution }\end{array}$ & + \\
\hline
\end{tabular}

Table 06: Thin Layer Chromatographic Analysis for Triterpenoids in Hydroalcoholic extract of Ipomoea aquatica

\begin{tabular}{|c|c|c|c|c|c|c|c|}
\hline $\begin{array}{l}\text { S. } \\
\text { No. }\end{array}$ & $\begin{array}{c}\text { Sample of } \\
\text { interest }\end{array}$ & $\begin{array}{l}\text { Mobile } \\
\text { phase }\end{array}$ & $\begin{array}{l}\text { Develop- } \\
\text { ment time } \\
(\text { min) }\end{array}$ & $\begin{array}{c}\text { Fluorescence } \\
\text { spot colour at } \\
365 \mathrm{~nm}\end{array}$ & $\begin{array}{c}\text { Distance } \\
\text { travelled } \\
\text { by the } \\
\text { solute } \\
\text { (cm) }\end{array}$ & $\begin{array}{c}\text { Solvent } \\
\text { Front }(\mathbf{c m})\end{array}$ & $\begin{array}{c}\mathbf{R}_{\mathbf{f}} \\
\text { value }\end{array}$ \\
\hline 1. & $\begin{array}{l}\text { Steroids and } \\
\text { Tri- } \\
\text { terpenoids }\end{array}$ & $\begin{array}{c}\text { Toluene: } \\
\text { Ethyl } \\
\text { acetate } \\
(9.3: 0.7 \\
\text { v/v) }\end{array}$ & 25 & $\begin{array}{l}\text { Blue } \\
\text { Green } \\
\text { Pink } \\
\text { Pink } \\
\text { Pink }\end{array}$ & $\begin{array}{l}0.7 \\
1.4 \\
2.9 \\
4.6 \\
7.5\end{array}$ & 12.8 & $\begin{array}{l}0.06 \\
0.11 \\
0.23 \\
0.36 \\
0.59\end{array}$ \\
\hline
\end{tabular}

\section{Conclusion:}

Mostly polar compounds exhibit pharmacological actions. In addition to that, these lipophilic triterpenoids also play a great role in giving therapeutic activities. Hence, this research will have support for the isolation, characterization and activity studies on the mentioned herbal for researchers in herbal industries, botanist, institutions, agricultural and pharmaceutical fields.

\section{Acknowledgement:}

This analysis was encouraged by the Management and Principal of Karpagam Educational Institutions, Coimbatore. We thank our colleagues from Karpagam College of Pharmacy and Faculty of Pharmacy, 
Karpagam University, Karpagam Academy of Higher Education, Coimbatore, who contributedacumen and dexterity that greatly reinforced the exploration.

\section{References:}

1. Tetracyclic Triterpenoids in Herbal Medicines and their Activities in Diabetes and its Complications (PDF Download Available). Available from: https://www.researchgate.net/publication/278789662_Tetracyclic_Triterpenoids_in_Herbal_Medicines _and_their_Activities_in_Diabetes_and_its_Complications [accessed May 11, 2017].

2. Harborne, J.B. Phytochemical Methods; A guide to Modern Techniques of Plant Analysis,Chapman and Hall Ltd., London, Great Britain. 1998:182-190.

3. Cai, L. Thin Layer Chromatography. Current Protocols Essential Laboratory Techniques. (2014) 6.3.16.3.18.

4. Nyamweru. B. C, Kaale. E, Manyanga. V. P, Chambuso. M and Layloff. T. Development and Validation of a Thin-Layer Chromatographic-Densitometric Method for the Analysis of Ciprofloxacin Hydrochloride Tablets. Journal of Planar Chromatography. (2013) 26; 4, 370-374.

5. Spangenberg B and. Kaiser. R. E. The Water Content of Stationary Phases. Journal of Planar Chromatography. (2007). 21 (5) 307-308.

6. Scott. R. M. The Stationary Phase in Thin Layer Chromatography. Journal of Liquid Chromatography. 2006:4(12):2147-2174.

7. https://www.medicinalplants-pharmacognosy.com/pharmacognosy-s-topics/extraction-methods/

8. http://agritech.tnau.ac.in/horticulture/extraction_techniques\%20_medicinal_plants.pdf.

9. S.S. Khadabadi, S.L. Deore and B. A. Baviskar. Experimental Phytopharmacognosy - A Comprehensive guide. NiraliPrakashan, Pune, Maharashtra. Second edition, 2013:p.3.1-3.13, A 1.1-2.8.

10. C. K. Kokate, A.P. Purohit and S. B. Gokhale. Pharmacognosy, $51^{\text {st }}$ edition, NiraliPrakashan, Pune, Maharashtra. 2015: p. A.23-A.27.

11. ChitrajitMalakar and PinakPaniNathChoudhury. Pharmacological Potentiality and Medicinal Uses of Ipomoea AquaticaForsk: A Review. Asian J Pharm Clin Res. 2015; 8(2):60-63.

12. ManjulikaYadav, SanjuktaChatterji, Sharad Kumar Gupta and GeetaWatal. Preliminary Phytochemical Screening of Six Medicinal Plants used in Traditional Medicine. International Journal of Pharmacy and Pharmaceutical Sciences. 2014;6(5):539-542.

13. MamtaSaxena, JyotiSaxena, Rajeev Nema, Dharmendra Singh and Abhishek Gupta. Phytochemistry of Medicinal Plants. Journal of Pharmacognosy and Phytochemistry. 2013;1(6):168-182.

14. K. Selvaraj, RanjanaChowdhury and ChiranjibBhattacharjee. Isolation and structural elucidation of flavonoids from aquatic fern Azollamicrophyllaand evaluation of free radical scavenging activity. International Journal of Pharmacy and Pharmaceutical Sciences. 2013;5(3):743-749.

15. Salna KP, Sreejith K, Uthiralingam M, Mithu A Prince, John Milton MC and Albin T Fleming. A Comparative Study of Phytochemicals Investigation of Andrographispaniculata and Murrayakoenigii. International Journal of Pharmacy and Pharmaceutical Sciences. 2011;3(3):291-292.

16. Daya L. Chothani, M. B. Patel and S. H. Mishra. HPTLC Fingerprint Profile and Isolation of Marker Compound of Ruellia tuberose. Chromatography Research International. 2012; 2012:1-6.

17. Peach and Tracey, M.V., Modern Methods of plant Analysis, Springer \&Verlag, Berlin, Vol.III, 321322(1955).

18. Peach, K. and Tracy, M.V., "Modern Methods of Plant Analysis", Vol. III, Springer-Verlag, Berlin, 64 \& 464 (1955).

19. Singh J, Bagchi GD, Khanuja SPS (2003). Manufacturing and quality control of Ayurvedic and herbal preparations, In: Verpoorte, R. and Mukherjee, P. K.(Eds), GMP for Botanicals, Regulatory and Quality Issues on Phytomedicine (1st Edition), Business Horizons, New Delhi, p. 201-230.

20. E. Stahl, "Thin layer chromatography," in A Laboratory Hand Book, Springer, Berlin, Germany, 2nd edition, 1965.

21. Sethi P.D. Quantitative Analysis of Pharmaceutical Formulations, High Performance Thin Layer Chromatography. CBS Publishers and Distributors, New Delhi, India, 1996: 1-30.

22. Snyder, L.R., Kirkland, J.J., Glajch, J.I.,Practical HPLC Method Development. 2nd ed. 13. 1997, 21173. 
23. http://www.separationsnow.com/details/journal/sepspec1715journal/PhytochemicalAnalysis.html?tzcheck=1.

24. D.A.Skoog, F.J.Holler and T.A. Nieman. Principles of instrumental analysis. 5th edition. Saunders college publishing. 2006:761-766.

25. E. Dreassi, G. Ceramelli and P. Corti. Thin-layer chromatography in pharmaceutical analysis. In practical thin-layer chromatography — a multidisciplinary approach. Fried b., Sharma J. (eds.) Crc press, Boca Raton, fl, 1996:231.

26. G. Szepesi and M. Gazdag. Steroids. In handbook of thin layer chromatography. Sharma G, Fried B (eds.) Marcel Dekker, New York. 1996:971.

27. G.Justus and Kirchner. Thin-layer chromatographic quantitative analysis. Journal of Chromatography a1. 1973;82(1):101- 115 .

28. G.R. Chatwal and S.K Anand. Instrumental methods of chemical analysis. 5th edition. Himalaya publishing house. 2008:2.599-2.616.

29. H.T. Quach, R.L. Steeper and G.W.Griffin. Separation of plant pigments by thin layer chromatography. Journal of Chemical Education. 81.2004.385-7.

30. M Ali and V. Agrawal. Thin-layer chromatography of aromatic amines, Separation Science and Technology. 37. 2002:363-377.

31. R.M. Scott. Clinical analysis by thin-layer chromatography techniques. Ann Arbor science publishers. Ann Arbor, mi. 1969.

32. S Singhal, N singhal and S Agarwal. Pharmaceutical analysis-II. Thin Layer Chromatography. First edition. PragatiPrakashan. 2009:98-111.

33. VidyaSagar. Instrumental methods of drug analysis. First edition. Pharma Med Press. 2009:263.

34. Ranjith Kumar D, Mohan S., Vanathi P., Prakash G., Sasikala M., Karpakavalli M. Development and Validation of UV Spectroscopic Method for Estimation of Milrinone in Formulation. World Journal of Pharmaceutical Research. 2016,5(4):1501-1508.

35. Sasikala M., Karpakavalli M., Ranjithkumar D., Prakash G., Vanathi P., Mohan S. In-vitro free radical scavenging activity studies of extracts and isolated compounds of Eugenia jambolana lam. Seeds. World Journal of Pharmaceutical Research. 2016;5(6): 2021-2030.

36. Sasikala M., Karpakavalli M., Vanathi P., Ranjithkumar D., Prakash G., Mohan S. Validated UV spectrophotometric method development for evaluation and stability analysis of Tolvaptan in bulk drug and its formulation. World Journal of Pharmacy and Pharmaceutical Sciences. 2016; 5(6):20482063.

37. Karpakavalli M, Sangilimuthu AY, Sasikala M, Komala M, Ranjithkumar D and Mohan S. A Predominant Evaluation of Viable Templates for Asthma Therapy Exerting an In silico Analog Method, Virtual Library Screening. Journal of Chemical and Pharmaceutical Research. 2017; 9(1):43-53.

38. Sasikala M, SundaraGanapathy R, Karpakavalli $M$ and Mohan S. Chemotaxonomical and pharmacological review on medicinal plants in temperate region. International Journal of Pharmacy \& Technology. 2017;9(1 ): 29165-29172. 
Extra page not be printed.

For your Research References requirements-

Log on to www.sphinxsai.com

International Journal of ChemTech Research

$* * * * *$ 